\title{
Temporal Change in Fur Color in Museum Specimens of Mammals: Reddish-Brown Species Get Redder with Storage Time
}

\author{
Andrew K. Davis, ${ }^{1}$ Natalie Woodall, ${ }^{1}$ Jake P. Moskowitz, ${ }^{1}$ \\ Nikole Castleberry, ${ }^{2}$ and Byron J. Freeman ${ }^{2}$ \\ ${ }^{1}$ Odum School of Ecology, The University of Georgia, Athens, GA 30602, USA \\ ${ }^{2}$ Georgia Museum of Natural History, The University of Georgia, Athens, GA 30602, USA \\ Correspondence should be addressed to Andrew K. Davis; akdavis@uga.edu
}

Received 25 March 2013; Accepted 13 May 2013

Academic Editor: Randy J. Nelson

Copyright ( $) 2013$ Andrew K. Davis et al. This is an open access article distributed under the Creative Commons Attribution License, which permits unrestricted use, distribution, and reproduction in any medium, provided the original work is properly cited.

\begin{abstract}
Museum collections have great value for zoological research, but despite careful preservation, over time specimens can show subtle changes in color. We examined the effect of storage time on fur color of two reddish-brown species, golden mice (Ochrotomys nuttalli) and eastern chipmunk (Tamias striatus). Using image analysis, we obtained color data (hue, saturation, and density) on 91 golden mice and 49 chipmunks from Georgia, USA. Analyses that considered body size, gender, and collection year showed significant effects of year on fur color of golden mice (hue and saturation) and of agouti color of chipmunks. Older specimens tended to be redder in color than newer specimens, consistent with a prior study of red bats (Lasiurus borealis). Hair samples showed reddening of fine body hairs, but not in thicker guard hairs. There was no temporal change in black or white stripe color in chipmunks, indicating that this temporal effect would be limited to species with reddish-brown fur. This effect may be caused by breakdown of eumelanin pigments (which make dark colors) over time, leaving a greater proportion of pheomelanin pigments (which make red colors). These results show that storage time needs to be considered in research projects where fur color is of importance.
\end{abstract}

\section{Introduction}

Museum collections of animals have always been a valuable resource for zoological research. Older specimens in particular offer insights into the past and allow researchers to track the historical incidence of deformities [1], document species declines [2], and extract DNA for genetic analyses [3]. An implicit assumption with all museum collections is that once a specimen is added to a collection and properly stored, it remains unchanged through time. In a recent museum study of pelage color in red bats (Lasiurus borealis), a curious discovery was made, where older specimens tended to have redder shades of pelage than did newer specimens [4], which is the opposite patter one would expect if specimens simply faded over time. Indeed, color fading does happen when specimens (of most taxa) are exposed to light $[5,6]$ such as in museum exhibits. However, these bat specimens had always been housed in drawers within standard metal museum cabinets (i.e., in darkness). At the time, it was thought that this was from breakage of buffy-tipped hair fibres on older specimens. Since that study, we have examined two additional mammal species in this same museum to look for evidence of temporal color changes in their fur, and we report the results of these investigations here.

Aside from the previous study, there have been no previous investigations of mammalian pelage color in museum collections. In contrast, numerous investigators have searched for temporal changes in coloration of birds in museum collections, with varying results $[7,8]$. While many of these studies focused on the bright carotenoid-based pigments of bird feathers, one study also examined the black (melanin-based) color of bird specimens [9], and these results 


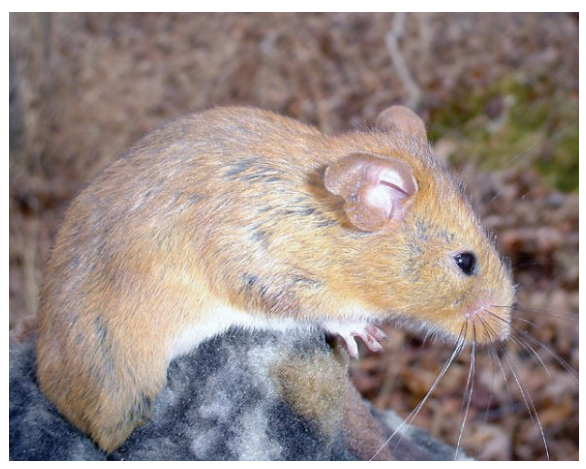

(a)

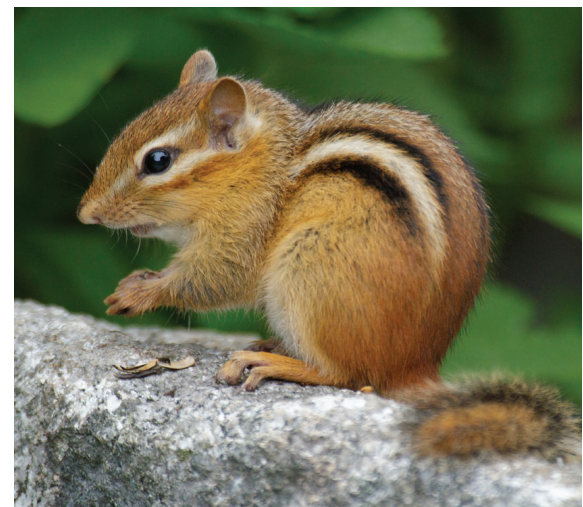

(b)

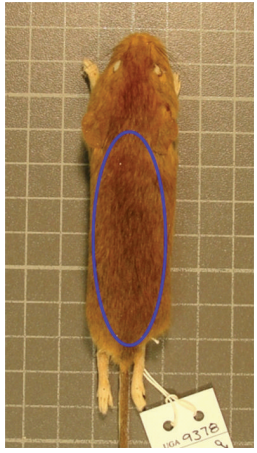

(c)

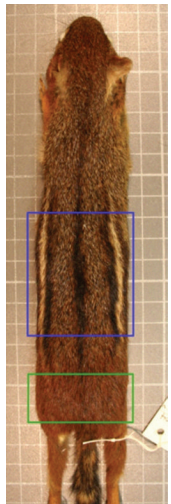

(d)

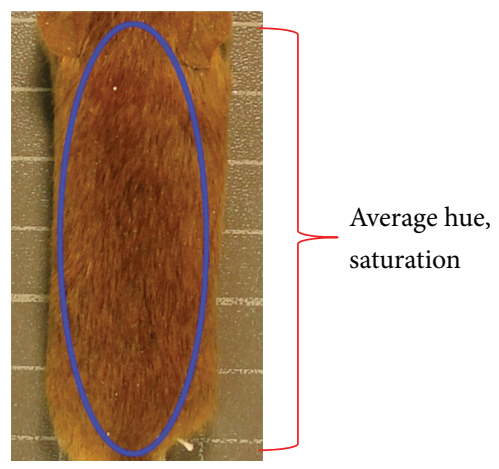

(e)

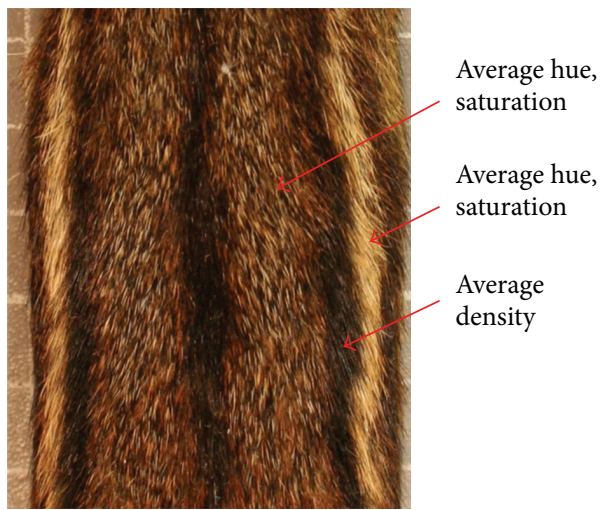

(f)

FIGURE 1: Photographs of the two species studied, golden mouse (a) and chipmunk (b), and method of measuring color from photographs. Specimens were photographed ((c) and (d)), and image analysis software was used to measure fur color in the selected areas ((e) and (f); see Section 2 for color measurement). The agouti, white, and black stripes of chipmunks (f) were measured separately. Rump color (green box in (d)) was also measured in chipmunks. Photo credits: Josh Campbell (a) and Richard Cameron (b).

would be helpful for comparison to the melanin-based color of mammals. Doucet and Hill [9] showed how feathers with melanin-based colors tended to have higher red chroma in older specimens. Since all melanin-based color is formed by a combination of two melanin pigments, eumelanin (which makes dark colors) and pheomelanin (which makes yellow to red colors), they speculated that eumelanin may be more susceptible to degradation than pheomelanin pigments, which over time could lead to reduced proportions of this pigment in the feathers, ultimately resulting in higher reflectance at longer wavelengths (i.e., giving the feathers a slightly reddish color). This is in agreement with at least one anecdotal account from a seasoned museum curator who indicated that of the two melanin pigments, eumelanin tends to become paler and redder over time, while pheomelanin becomes paler with age (personal communication cited in [10]).

Our primary objective of the current study was to determine if the temporal change in color seen in the previous red bat study [4] could be seen in other species (with reddish-brown fur) in museum collections. The species examined were golden mouse (Ochrotomys nuttalli) and eastern chipmunk (Tamias striatus), which both are native to the United States (although we only examined specimens from Georgia; see Section 2). As their name suggests, golden mice have fur that has a golden-brown or tan color throughout (Figure 1(a)). The eastern chipmunk has a mixture of agouti and reddish-brown fur, with white and black dorsal stripes (Figure 1(b)). Including chipmunks in this study allowed us to compare effects of storage on all fur colors (agouti, black, white, and red). Results of this investigation will bear on all projects where color of mammal skins is of importance and moreover will further enhance understanding of the effects of long-term storage on animal tissues.

\section{Methods}

2.1. Museum Specimens. Specimens of each species were obtained from the Georgia Museum of Natural History, in Athens, GA (USA). While this museum holds specimens from throughout the southeastern United States, we limited our analyses here to animals from the State of Georgia, to minimize the possibility of comparing different races or animals that may be locally adapted to differing climates. The collection of golden mice from Georgia contained 91 specimens that had been collected between 1935 and 1996. The eastern chipmunk collection from Georgia consisted of 49 specimens collected between 1946 and 1996. All had been 
prepared in a similar manner, that is, as skins placed in a standardized position (see Figure 1), and with no chemicals or preservatives applied to the pelage. All specimens were stored in drawers within metal cabinets and were kept as such, as well as in complete darkness, for the entirety of their storage life. From the information on the specimen tags, we recorded the gender and total length of each animal prior to photography (later).

2.2. Measuring Pelage Color. Regardless of species, each animal was individually positioned directly under a digital camera on a copystand and photographed (see Figure 1). The same copystand was used for both collections, but at two separate times. Golden mice were photographed on January 1,2011 , while chipmunks were photographed on January 17 , 2013 (although actual dates and times of photography should be meaningless in this study). All photography was done in a room in the museum. In all cases, no camera flash was used; artificial lighting was directed toward the specimen from both sides of the camera (using side-mounted lights on the copystand) so at least within each collection, the lighting for all specimens was standardized. This was important since we were interested only in the relative differences among individuals within the mice or chipmunk collections, not in comparing mice versus chipmunk colors.

From the photographs we used image analysis procedures to quantify the degree of redness in the specimens $[4,11,12]$. For this, images were imported into Adobe Photoshop with FoveaPro plugins installed (http://www .reindeergraphics.com/). For the golden mice, an oval selection was drawn over the dorsal surface that covered as much of the furred area as possible without touching the ears (Figure 1). Using a FoveaPro plugin, the average pixel hue and saturation values of this selected area were obtained. With computer software, hue is measured in degrees (0-360), with lower scores representing redder colors, while brightness is measured from 0 to 255 , with higher scores indicating purer colors. From the chipmunk specimens we first selected a square region of the dorsal surface that encompassed the striped region on the dorsum (Figure 1), and then within this box we measured color of the agouti, black, and white stripes individually. For this, one of us traced the edge of the stripes on the left and right sides, and we obtained the hue and saturation within these traced areas. For the agouti pelage and white dorsal stripes, we obtained the average hue and saturation scores. For the black dorsal stripes, we obtained the average pixel density score of the traced area, which is a measure of "blackness" and ranges from 0 to 255, with 0 being perfect black and 255 perfect white [13]. These values were obtained for the left and right sides and averaged for each specimen. Finally, we also measured the hue and saturation of the rump of each chipmunk, which we defined as the region from the base of the tail to where the dorsal stripes end (Figure $1(\mathrm{~b})$ ). This region consists of only reddish-brown fur.

2.3. Data Analyses. All pelage hue, saturation, and density values of the golden mice and chipmunks were normally distributed, based on visual inspection of their frequency distributions. We therefore used General Linear Modeling to determine if pelage color of either species varies through time. For the golden mice, both hue and saturation were used as dependent variables, gender was a predictor, and body size (i.e., total length) and collection year were covariates. A similar approach was used to examine color in chipmunks, although here we separately examined each color type, including the agouti, white, and black stripes of the dorsum and the red color of the rump. All analyses were conducted using the Statistica 6.1 software package [14].

\section{Results}

In the golden mice specimens, there was no significant effect of body size on pelage hue $\left(F_{1,84}=0.951, P=0.332\right)$, nor was there a difference between males and females $\left(F_{1,84}=\right.$ $0.987, P=0.323)$. There was a nearly significant effect of collection year $\left(F_{1,84}=3.819, P=0.054\right)$, with more recent specimens tending to have larger hue scores (less red; Figure 2(a)). The analysis of pelage saturation of golden mice showed significant variation with body size $\left(F_{1,84}=16.96\right.$, $P<0.001)$, no effect of gender $\left(F_{1,84}=1.82, P=0.180\right)$, and a significant relationship with collection year $\left(F_{1,84}=13.43\right.$, $P<0.001)$, such that more recent specimens had lower saturation scores (their color was less pure; Figure 2(a)).

In the analysis of dorsal agouti color in the chipmunks, there was no effect of body size $\left(F_{1,42}=0.173, P=0.679\right)$ nor of gender $\left(F_{1,42}=0.549, P=0.462\right)$ on hue, but a significant effect of collection year $\left(F_{1,42}=7.71, P=\right.$ $0.008)$, with more recent specimens having higher hue scores (Figure 2(b)). There was no effect of body size $\left(F_{1,42}=0.087\right.$, $P=0.769)$ or gender $\left(F_{1,42}=0.626, P=0.433\right)$ on the agouti saturation scores, but a significant effect of collection year $\left(F_{1,42}=7.83, P=0.007\right)$, with more recent specimens having lower saturation scores (Figure 2(b)). Results of the analyses of white and black dorsal stripes on the chipmunks showed no effects of gender, body size, or collection year, on white hue, saturation, or the black density scores $(P>$ 0.1 for all predictor variables in all models). Results of the analyses of hue and saturation of the chipmunk rump color were nearly identical to the analyses of agouti color (i.e., with the same significant predictor variables) and are not reported here.

In sum, while the magnitude of the effect differed by species, results from analyses of golden mice and chipmunk color (at least for the agouti fur) were qualitatively similar; specimens from earlier years tend to be redder than those from more recent years. This pattern can be visually seen when photos of representative early and later specimens of each species are cropped at the region of interest (middle of the dorsum) and placed side-by-side (Figure 3 ).

\section{Discussion}

Results from this study are consistent with the prior investigation of red bats from Georgia (from the same museum), in which older specimens were found to be redder in color 

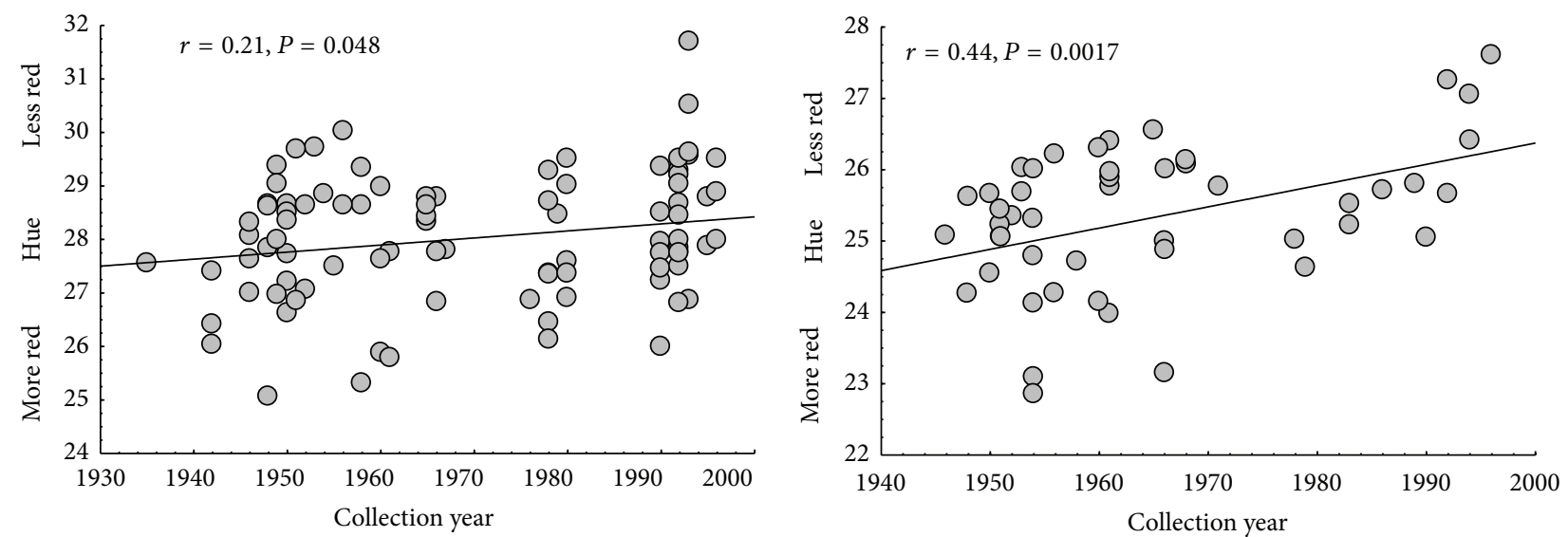

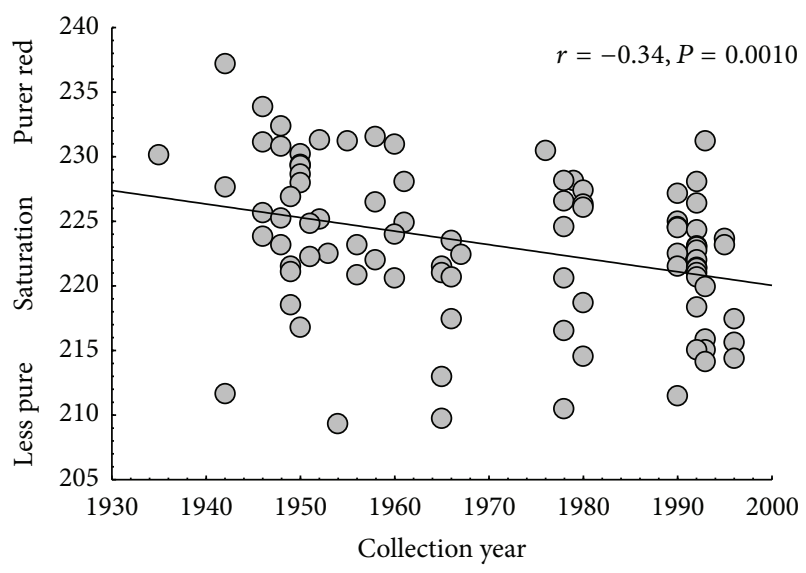

(a) Golden mouse

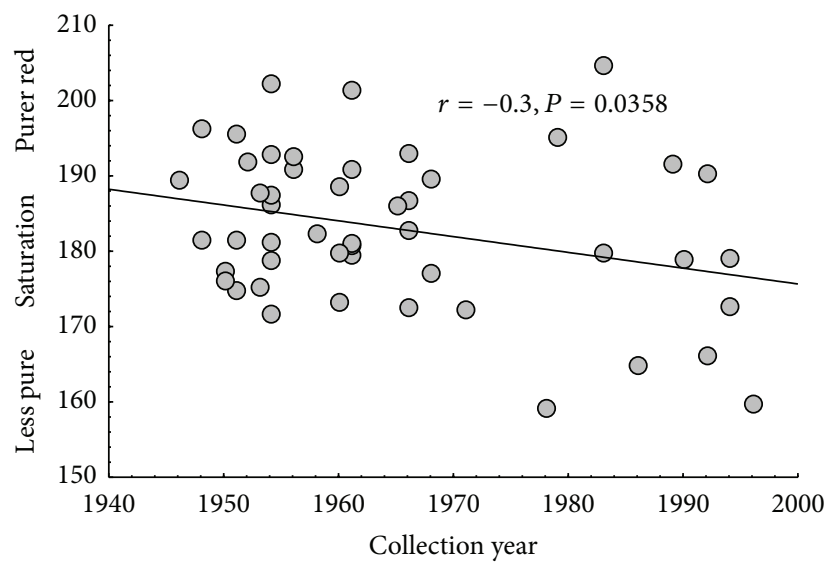

(b) Chipmunk (agouti fur only)

FIGURE 2: Relationships between storage time (collection year) and pelage color (hue and saturation) for golden mice (a) and chipmunks (b). Only the values from the agouti pelage of chipmunks are shown. There was no temporal effect on the white and black stripes of chipmunks.

than more recent specimens [4]. At the time, it was thought that this pattern was the result of breakage of hair shaft tips in older specimens, although further examination of the bat collection as well as the species considered here found no evidence for hair breakage. This can be seen in digital scans of hair samples (of the agouti fur) taken from early and later chipmunk specimens, which show intact guard hairs in both cases (Figure 4). However, these scans also reveal that much of the color variation between older and newer specimens is in the fine body hair of the animals, rather than the thicker guard hairs. In the older specimens, these fine hairs appear redder than in the newer specimens. Meanwhile, the thick guard hair appears unchanged. It may be that the thickness and size of the hair determine its susceptibility to color change. This could also explain why we saw no temporal effect on the white and black dorsal stripes of the chipmunks, which consist primarily of white or black guard hairs (see Figure 3).

We therefore have similar results now from three different mammal species from Georgia, all with distinct life histories, habitat preferences, and so forth. Because of these differences in biology and life history, the mechanism behind the temporal pattern must be common to all three. The simplest explanation is that the fur of all three species undergoes certain biochemical changes in storage, such as breakdown of eumelanin pigment in the hair fibers, which was speculated by Doucet and Hill [9]. Over time this would result in greater proportions of the redder pheomelanin pigment in the fur and a redder overall coat color in older specimens. If this is indeed the case, it emphasizes the importance of considering storage time in research studies using mammal skins and where color is of importance.

There is also the possibility that early collectors may have used different methods to prepare study skins at this museum, which in some cases can cause reddening of pelage [15]. In particular, soaking the skin in tap water to relax it prior to stuffing appears to cause pelage reddening, and this effect can be seen in most mammal species, but especially in squirrels [15]. However, while most of the collectors of the earliest specimens (prior to 1960) at the Georgia Museum of Natural History have since passed, there is consensus among the current workers that specimens have always been prepared here according to standard mammalogy guidelines [16], which does not include soaking. 

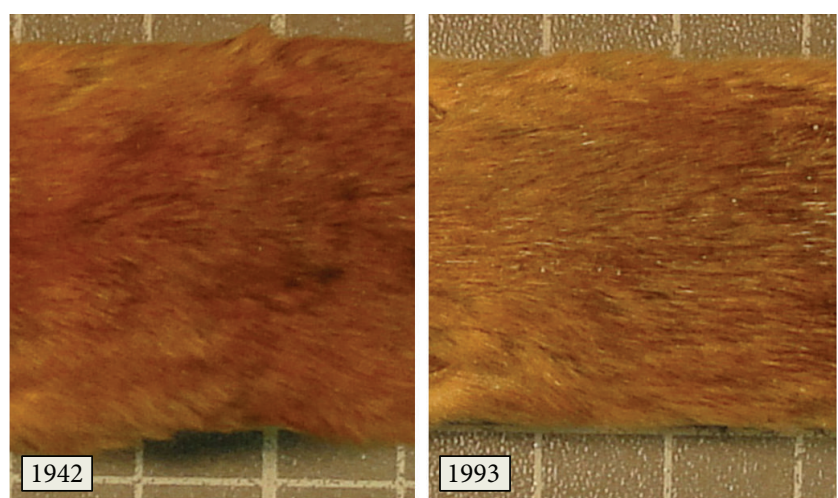

(a)
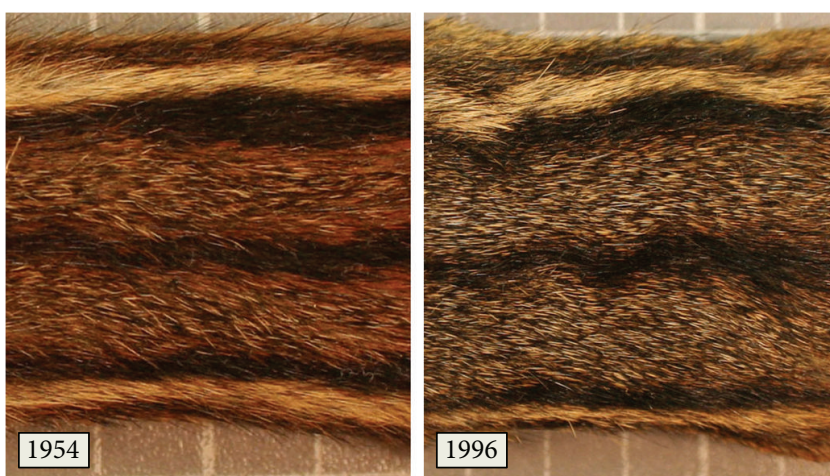

(b)

FIGURE 3: Comparison of representative older and newer specimens of golden mice (a) and chipmunks (b), cropped to show the region measured.

Results from this study lead us to wonder how prevalent this phenomenon is in mammalian collections here and in other museums. While our intention here was only to confirm the existence of the temporal effect found in the prior study of red bats (and we therefore only chose species that had reddish fur, similar to red bats), the lack of color change found in the black and white chipmunk fur suggests that this effect may only be observed in species with reddish fur. Moreover, it may be that species with especially fine hairs would also be susceptible to change (since the fine body hairs of chipmunks changed more than the guard hairs).

A variety of scientific investigations, spanning many decades, have incorporated measures of pelage color of museum specimens (e.g., [17-20]). Such studies require that all specimens accurately represent their "true" color (i.e., their color at the time and place of collection). Given this temporal pattern found here, it would be wise for future investigators to consider storage time in all analyses of mammalian color, especially for species with reddish-brown fur.

\section{Acknowledgments}

The authors thank Sonia Altizer for use of lab space and Liz McGhee for assistance with obtaining specimens. Gary

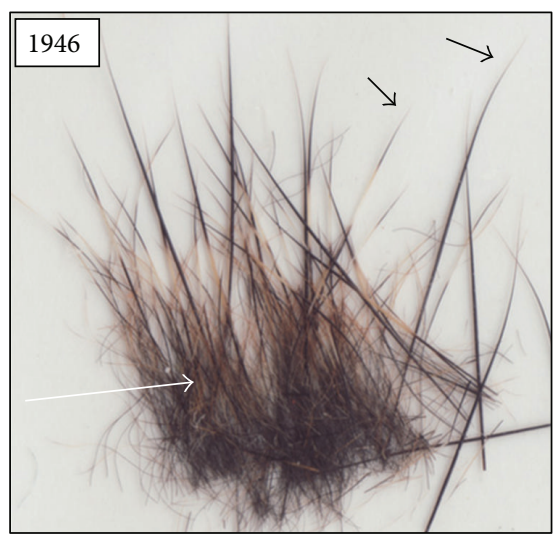

(a)

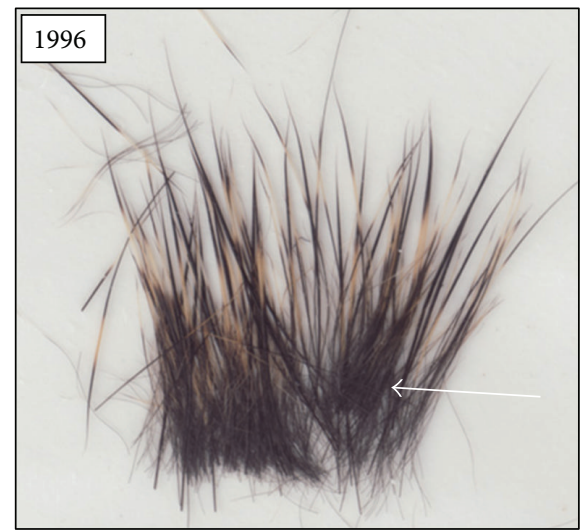

(b)

FIGURE 4: Scans of hair samples taken from an older chipmunk specimen and a newer chipmunk specimen, to show differences in color. Hair samples were scanned on a flatbed scanner with no color correction. Samples were cut from the agouti fur on the dorsum of the specimens. Note the red coloring of the fine body hair in the older specimen, compared to the newer specimen (white arrows) and that there is no breakage of hair tips in the older specimen (black arrows).

Barrett contributed helpful comments on the project and on the biology of golden mice.

\section{References}

[1] P. T. J. Johnson, K. B. Lunde, D. A. Zelmer, and J. K. Werner, "Limb deformities as an emerging parasitic disease in amphibians: evidence from museum specimens and resurvey data," Conservation Biology, vol. 17, no. 6, pp. 1724-1737, 2003.

[2] H. B. Shaffer, R. N. Fisher, and C. Davidson, "The role of natural history collections in documenting species declines," Trends in Ecology \& Evolution, vol. 13, no. 1, pp. 27-30, 1998.

[3] A. C. M. Junqueira, A. C. Lessinger, and A. M. L. Azeredo-Espin, "Methods for the recovery of mitochondrial DNA sequences from museum specimens of myiasis-causing flies," Medical and Veterinary Entomology, vol. 16, no. 1, pp. 39-45, 2002.

[4] A. K. Davis and S. B. Castleberry, "Pelage color of red bats Lasiurus borealis varies with body size: an image analysis of 
museum specimens," Current Zoology, vol. 56, no. 4, pp. 401405, 2010.

[5] W. B. McKillop, "Induced colour fading in entomological specimens," J. Waddington and D. M. Rudkin, Eds., pp. 101104, Proceedings of the Workshop on Care and Maintenance of Natural History Collections Royal Ontario Museum, Toronto, Canada, 1986.

[6] J. Hudon, "Considerations in the conservation of feathers and hair, particularly their pigments," in Fur Trade Legacy. The Preservation of Organic Materials, M. Brunn and J. A. Burns, Eds., pp. 127-147, Canadian Association for Conservation of Cultural Property, Ottawa, Canada, 2005.

[7] G. D. McNett and K. Marchetti, "Ultraviolet degradation in carotenoid patches: live versus museum specimens of wood warblers (Parulidae)," Auk, vol. 122, no. 3, pp. 793-802, 2005.

[8] J. K. Armenta, P. O. Dunn, and L. A. Whittingham, "Effects of specimen age on plumage color," Auk, vol. 125, no. 4, pp. 803808, 2008.

[9] S. M. Doucet and G. E. Hill, "Do museum specimens accurately represent wild birds? A case study of carotenoid, melanin, and structural colours in long-tailed manakins Chiroxiphia linearis," Journal of Avian Biology, vol. 40, no. 2, pp. 146-156, 2009.

[10] C. A. Hawks, S. L. Williams, and J. S. Gardner, The Care of Tanned Skins in Mammal Research Collections. Museology, vol. 6, Texas Tech University Publication, 1984.

[11] A. K. Davis, "Wing color of monarch butterflies (Danaus plexippus) in Eastern North America across life stages: migrants are "redder" than breeding and overwintering stages," Psyche, vol. 2009, Article ID 705780, 5 pages, 2009.

[12] A. K. Davis, J. Chi, C. A. Bradley, and S. Altizer, "The redder the better: wing color predicts flight performance in monarch butterflies," PloS ONE, vol. 7, no. 7, Article ID e41323, 2012.

[13] A. K. Davis, B. D. Farrey, and S. Altizer, "Variation in thermally induced melanism in monarch butterflies (Lepidoptera: Nymphalidae) from three North American populations," Journal of Thermal Biology, vol. 30, no. 5, pp. 410-421, 2005.

[14] Statistica, Statistica Version 6. 1, Statsoft Inc., 2003.

[15] S. C. Downing, "Color changes in mammal skins during preparation," Journal of Mammalogy, vol. 26, pp. 128-132, 1945.

[16] A. F. DeBlase and R. E. Martin, "A manual of mammalogy with keys to the families of the world," in Specimen Preparation and Preservation, chapter 35, Wm. C. Brown Company Publishers, Dubuque, Iowa, USA, 2nd edition, 1981.

[17] H. H. Collins, "Studies of the pelage phases and of the nature of color variations in mice of the genus Peromyscus," Journal of Experimental Zoology, vol. 38, pp. 45-107, 1923.

[18] R. H. Pine, J. E. Rice, J. E. Bucher, D. H. Tank, and A. M. Greenhall, "Labile pigments and fluorescent pelage in didelphid marsupials," Mammalia, vol. 49, pp. 249-256, 1985.

[19] L. N. Carraway and B. J. Verts, "Geographic variation in pelage color of piñon mice (Peromyscus truei) in the northern Great Basin and environs," Western North American Naturalist, vol. 62, no. 4, pp. 458-465, 2002.

[20] D. Ge, A. A. Lissovsky, L. Xia, C. Cheng, A. T. Smith, and Q. Yang, "Reevaluation of several taxa of Chinese lagomorphs (Mammalia: Lagomorpha) described on the basis of pelage phenotype variation," Mammalian Biology, vol. 77, no. 2, pp. 113123, 2012. 

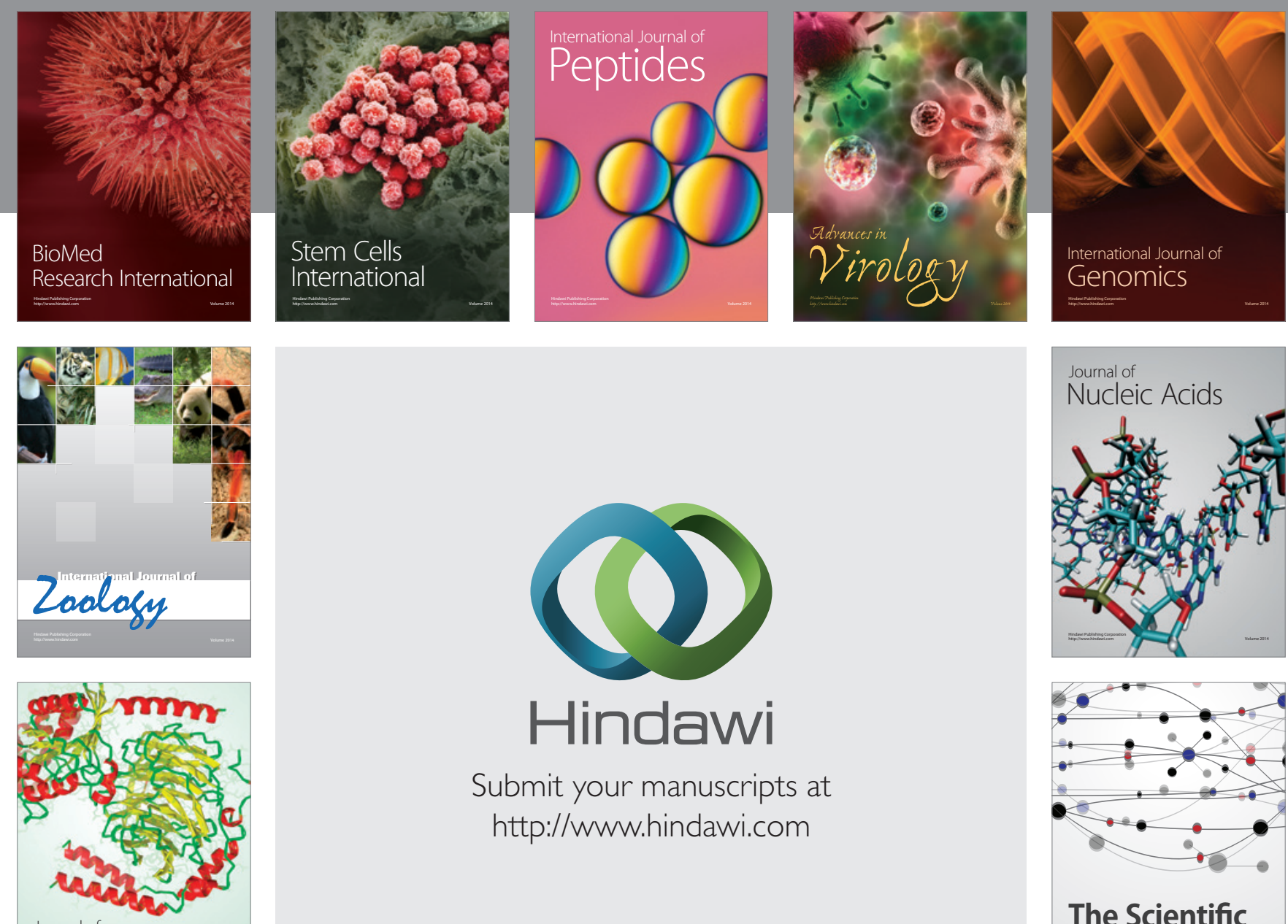

Submit your manuscripts at

http://www.hindawi.com

Journal of
Signal Transduction
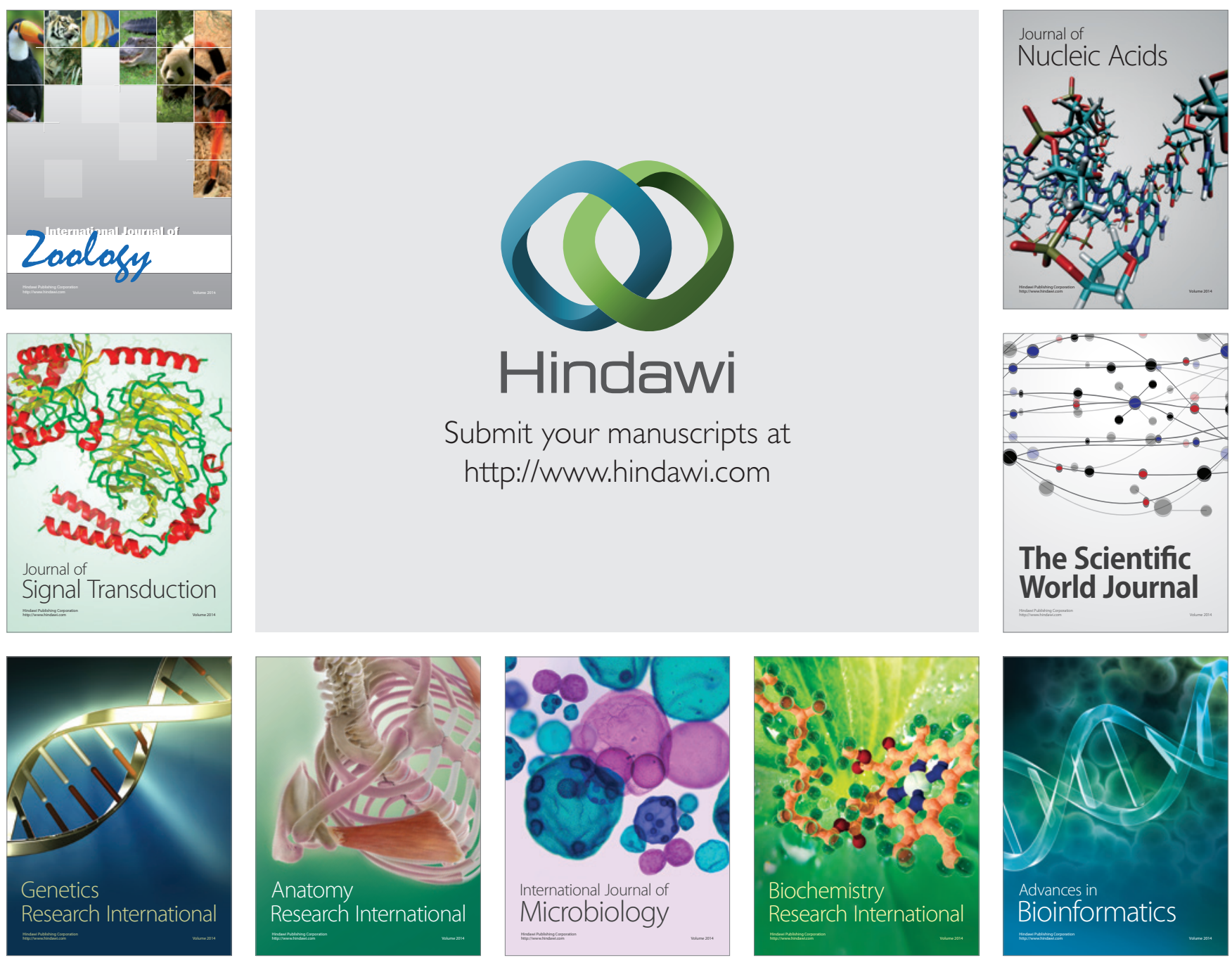

The Scientific World Journal
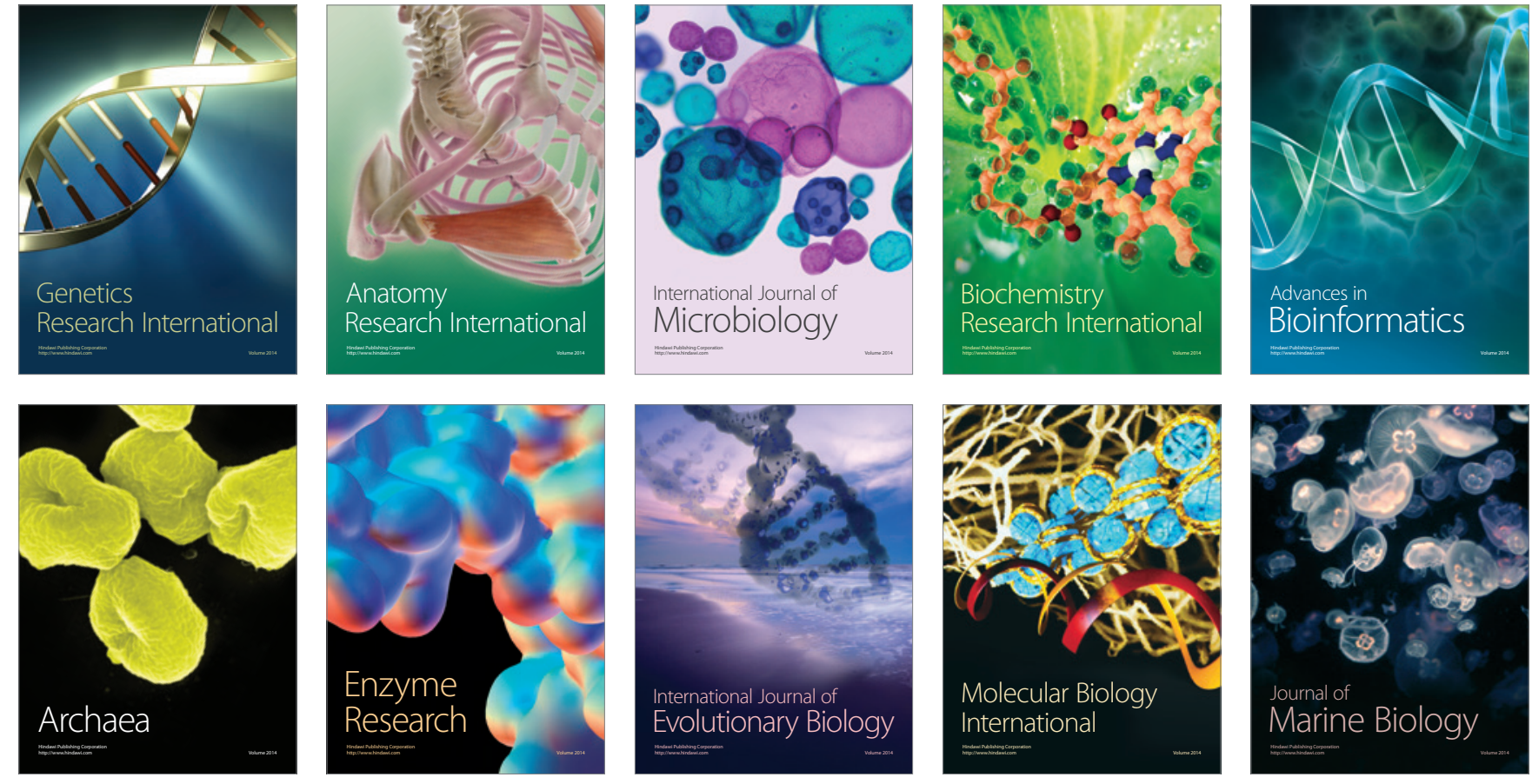